\title{
Risk factors for wound infection after minor surgery in general practice
}

\author{
Clare Heal, Petra Buettner and Sheldon Browning
}

S urgical site infection following minor surgery contributes to patient morbidity and compromises the cosmetic outcome. Most data regarding incidence and predictors of surgical site infection are based on hospital studies, ${ }^{1-3}$ and most studies looking at infection rates following minor dermatological surgery outside hospital have been conducted in specialist dermatology clinics. ${ }^{4-6}$ In contrast, the quality of evidence regarding infection rates following minor surgery in general practice seems to be poor, ${ }^{7}$ and a comprehensive MEDLINE search revealed only one study that adequately recorded the incidence of infection following minor surgery in general practice. $^{8}$

Skin excisions form a large proportion of a typical Australian general practitioner's workload, and this proportion is even greater in Queensland. ${ }^{9}$ In north Queensland, most suspicious skin lesions are managed by GPs, ${ }^{10}$ particularly in rural centres such as Mackay, where there is no resident dermatologist. There is evidence that performing minor surgery in general practice is cost-effective compared with a hospital setting. ${ }^{11}$ However, it is important to know the incidence of and risk factors for complications such as infection following minor surgery in general practice.

The data for this study were collected incidentally as part of a randomised controlled trial, which compared the standard management of keeping wounds dry and covered with allowing wounds to be uncovered and wet in the first 48 hours following minor surgery. ${ }^{12}$ As both arms of the trial showed equivalent infection rates at the 5\% significance level (intervention, 8.4\%; control, $8.9 \%$ ), they have been considered as a single group for the purpose of this study. Our aims in this study were to determine the incidence of and risk factors for surgical site infections following minor skin excisions in a primary care setting.

\section{METHODS}

The methods for our prospective study of patients presenting for minor skin excisions, conducted initially as a randomised controlled trial, have been described in detail elsewhere. ${ }^{12}$ Here we provide a general overview.

\section{ABSTRACT}

Objective: To determine the incidence of and risk factors for surgical site infections in general practice.

Design: Prospective, observational study of patients presenting for minor excisions.

Setting: Primary care in a regional centre, Queensland, October 2004 to May 2005.

Participants: 857 patients were assessed for infection.

Results: The overall incidence of infection was $8.6 \%(95 \% \mathrm{Cl}, 3.5 \%-13.8 \%)$. Excisions from lower legs and feet $(P=0.009)$ or thighs $(P=0.005)$, excisions of basal cell carcinoma $(P=0.006)$ or squamous cell carcinoma $(P=0.002)$, and diabetes $(P<0.001)$ were independent risk factors for wound infection.

Conclusion: Our results indicate the high-risk groups for surgery in a general practice setting, such as people with diabetes and those undergoing excision of a nonmelanocytic skin cancer or excision from a lower limb. Recognition of these groups could encourage more judicial use of prophylactic antibiotics and use of other interventions aimed at reducing infection rates.

MJA 2006; 185: 255-258

\section{Setting and participants}

Nineteen GPs from four practices in the Mackay area participated. Consecutive patients presenting for minor skin excisions between October 2004 and May 2005 were invited to take part. Practice nurses were responsible for recruiting patients and collecting demographic and clinical data. A body site map was used to define excision sites.

\section{Eligibility criteria}

All patients presenting to a participating GP for "minor skin excision" (except for skin excisions on the face) were eligible to participate. Patients were excluded if they were already taking oral antibiotics, if oral or topical antibiotics were clinically indicated immediately postoperatively, or if they were taking immunosuppressive drugs. Further exclusion criteria were lacerations, having a flap or two-layer procedure, and excision of sebaceous cysts (which were often already infected).

\section{Surgical wound management protocol}

Three 1-hour workshops were conducted for participating GPs to develop guidelines to ensure that excisions were managed in a standardised manner.

\section{Clinical outcomes}

Wounds were assessed for infection by the practice nurse or doctor on the day of removal of sutures, or sooner if the participant represented with a perceived infection.

We used a definition of wound infection adapted from standardised surveillance criteria for defining superficial surgical site infection, which we felt to be the closest to a "gold standard" available (Box 1). ${ }^{1}$

\section{Statistical analysis}

Incidence of infection is given with 95\% confidence intervals. Numerical data are summarised using mean (SD) when normally distributed, or median and interquartile range (IQR) when skewed.

Bivariate comparisons were conducted using $\chi^{2}$ tests (two categorical variables) and unpaired $t$ tests or non-parametric MannWhitney tests (categorical and numerical variables).

Multivariable generalised linear modelling was used to identify independent risk factors of infection after minor surgery. Relative risks with 95\% confidence intervals were estimated using the binomial distribution and the logarithmic link function. All variables that were not part of the final model (age, sex, month excision took place, management of wound, and significant medical condition other than diabetes) were assessed for potential confounding of the relationships between body site of skin lesion, histology of skin lesion, and diabetes with wound infection. 


\section{Definition of superficial surgical site infection*}

- Infection must occur within 30 days of excision.

- There must be purulent discharge from the wound, or the general practitioner must diagnose a wound infection, or the GP commences antibiotics.

- Stitch abscess must not be counted as an infection.

*Adapted from the Centers for Disease Control and Prevention's National Nosocomial Infections Surveillance System.

The statistical analysis took the cluster sampling design (four doctors' practices) into account. Throughout the analysis, $P$ values less than 0.05 (two-sided hypotheses) were considered significant.

The statistical analysis was conducted using SPSS for Windows, release 12 (SPSS Inc, Chicago, Ill, USA) and Stata for Windows, release 8 (StataCorp, College Station, Tex, USA).

\section{RESULTS}

\section{Participant characteristics}

Participating GPs were younger (median age, 44 years) and more predominantly female (64\%) than average for Australian GPs (modal age category, 45-54 years; 32\% female)

Of 1247 patients who attended for skin excisions during the collection period from October 2004 to May 2005, 377 were excluded (294 ineligible; 83 non-participants) (Box 2). There were no significant differences in the age (participants, 56.3 years [SD, 16.5]; non-participants, 58.1 years [SD, 16.2]; $P=0.208$ ) and sex (participants, $47.6 \%$ female; non-participants, $44.9 \%$ female; $P=0.407$ ) of participating and non-participating patients.

Thirteen patients were eventually lost to follow-up. Follow-up was completed in 857 patients (98.5\%).

\section{Infections}

Infection occurred in 74 of the 857 excisions (8.6\%; 95\% CI, 3.5\%-13.8\%). Infection rates for the four centres were $2.9 \%$, $7.8 \%, 10.0 \%$, and $10.2 \%(P=0.0496)$. Of all characteristics recorded, only the presence of diabetes was significantly correlated with a higher incidence of infection (diabetes, $18.2 \%$; no diabetes, $8.4 \% ; P=0.019$ ) (Box 3). Participants older than 60 years had a higher incidence of wound infection (12.4\%) than younger participants (5.6\%) $(P=0.056)$. Squamous cell carcinomas were most prone to be infected (13.5\%), and benign naevi $(2.5 \%)$ and seborrhoeic keratoses (0) were least likely to become infected. Of the 74 infections, 25 (34\%) occurred on the lower leg (below the knee) or foot. There was little variation in incidence of infection with the month in which the excision took place, with no evidence of increased infection during the hotter wet season $(P=0.527)$. There was no significant difference in time to removal of sutures between the infected and non-infected groups (median, 8 days, IQR, 7-10 days for both groups; $P=0.538$ ) .

Multivariable generalised linear modelling showed that the body sites legs and feet $(P=$ $0.009)$ and thighs $(P=0.005)$; the histological subtypes basal cell carcinoma $(P=0.006)$ and squamous cell carcinoma $(P=0.002)$; and prevalence of diabetes $(P<0.001)$ were independently correlated with wound infection (Box 4).

\section{DISCUSSION}

Our results suggest that diabetes, excisions from the lower leg and foot or thigh, and excisions of non-melanocytic skin cancer (squamous cell carcinoma and basal cell carcinoma) are independent risk factors for infection after minor surgery. The latter finding is consistent with a study conducted in a specialist dermatology clinic, which suggested that oncological surgery (excision of

\section{Reasons for exclusion of 377 patients from study}

\begin{tabular}{|c|c|c|}
\hline Reason & Number & $\%$ \\
\hline \multicolumn{3}{|l|}{ Ineligible } \\
\hline Face & 256 & $20.5 \%$ \\
\hline Biopsy & 10 & $0.8 \%$ \\
\hline Flap & 17 & $1.4 \%$ \\
\hline Immunosuppressed & 1 & $0.1 \%$ \\
\hline Antibiotics & 5 & $0.4 \%$ \\
\hline $\begin{array}{l}\text { Not returning for } \\
\text { removal of sutures* }\end{array}$ & 5 & $0.4 \%$ \\
\hline \multicolumn{3}{|l|}{ Non-participation } \\
\hline Refused & 67 & $5.4 \%$ \\
\hline Not invited ${ }^{\dagger}$ & 16 & $1.3 \%$ \\
\hline Total & 377 & $30.2 \%$ \\
\hline
\end{tabular}

* These five patients knew that they would not be able to return for the removal of sutures. †The practice nurse forgot to invite these patients to participate.

\section{Bivariate correlates between infection after minor surgery and participant and lesion characteristics}

\begin{tabular}{lrr} 
Characteristic & $\begin{array}{c}\text { Incidence } \\
\text { of infection } \\
\text { (74/857) }\end{array}$ & $P$ \\
\hline Age (years) & $6.2 \%$ & 0.057 \\
$\leqslant 40$ & $4.8 \%$ & \\
$41-50$ & $5.8 \%$ & \\
$51-60$ & $12.2 \%$ \\
$61-70$ & $12.7 \%$
\end{tabular}

Sex

Male

$10.2 \%$

0.135

Female

$6.9 \%$

Body site

Scalp and neck

$10.6 \%$

0.072

Trunk

$5.3 \%$

Arms and hands

$6.8 \%$

Thighs

$14.0 \%$

Legs and feet

$15.0 \%$

Histology of lesion

Melanoma

$7.7 \%$

0.118

Basal cell carcinoma

$11.4 \%$

Squamous cell carcinoma

$13.5 \%$

Benign naevus

$2.5 \%$

Dysplastic naevus

$10.5 \%$

Seborrhoeic keratosis

0

Solar keratosis

$9.6 \%$

Other

Date of excision

Wet season (December to

$9.3 \%$

0.527

February)

Dry season

$8.3 \%$

Diabetes

No

$8.4 \%$

0.019

Yes

$18.2 \%$

Other medical condition*

No

$8.3 \%$

0.324

Yes

$22.2 \%$

* Medical conditions recorded were chronic obstructive pulmonary disease (8), anaemia (1), "aspirin" (2), "steroids" (3), "warfarin" (2), ischaemic heart disease (1), and peripheral vascular disease (1). Results were adjusted for the cluster sampling design. 
skin cancer) is associated with a higher risk of infection. ${ }^{13}$ Body extremities, with reduced blood supply, have also previously been associated with a higher incidence of infection. $^{13}$

The overall incidence of infection in our study $(8.6 \%)$ was higher than we expected from published results in a similar general practice cohort $(1.9 \%)^{8}$ and a similar dermatology clinic cohort (2\%), ${ }^{4}$ although exclusion of facial excisions from our study, which may have a lower incidence of infection, ${ }^{13}$ may have falsely elevated our overall incidence of infection. Excluding patients for whom antibiotics would otherwise have been indicated postoperatively would, however, have lowered the infection rate. A German study in a university medical centre setting reported a similar infection rate of $8 \% .{ }^{6}$ However, it is difficult to compare the infection rate between different studies as different variables and methods were used. $^{5}$

Our study had several limitations. There are various characteristics influencing the occurrence of infections and, although information on as many variables as possible was recorded, it proved difficult to ensure that all possible predictors of infection were recorded. There were inadequate data recorded on suture size and patient occupation, and consequently, these factors could not be compared. We did not record smoking status, which may be a risk factor for surgical site infections. ${ }^{1,14}$ We also did not record the size of lesion excised, excision margins or overall wound area, and therefore we are unable to exclude the possibility that the increase in incidence of infection recorded for squamous cell carcinomas and basal cell carcinomas could be related to the size of the overall wound area rather than the histology. However, there is some evidence that more complicated procedures (flaps or skin grafts) are associated with increased infection rates, rather than the size of the excision. ${ }^{4}$ Exclusion of facial excisions and more complicated surgery such as flap or two-level procedures prevented analysis of infection rates in these subgroups, and subsequent comparisons.

Although diabetes was found to be independently correlated with wound infection, the prevalence of diabetes as well as other medically important conditions was probably under-recorded, and power was limited to analyse these subgroups.

Surgical training and technique of the GPs involved are potential confounders which would be difficult to quantify and were not

\section{Multivariable generalised linear modelling of relation between infection after minor surgery and participant and lesion characteristics}

\begin{tabular}{|c|c|c|c|c|c|}
\hline Characteristic & $\begin{array}{l}\text { Without infection } \\
\quad(n=783)\end{array}$ & $\begin{array}{l}\text { With infection } \\
\quad(n=74)\end{array}$ & $\begin{array}{l}\text { Relative } \\
\text { risk }\end{array}$ & $95 \% \mathrm{Cl}$ & $P$ \\
\hline \multicolumn{6}{|l|}{ Age (years) } \\
\hline$\leqslant 40$ & 151 & 10 & 1 & & \\
\hline $41-50$ & 139 & 7 & 0.67 & $0.37-1.2$ & 0.190 \\
\hline $51-60$ & 162 & 10 & 0.69 & $0.42-1.1$ & 0.139 \\
\hline $61-70$ & 166 & 23 & 1.4 & $0.66-2.8$ & 0.406 \\
\hline$>70$ & 165 & 24 & 1.2 & $0.62-2.5$ & 0.534 \\
\hline \multicolumn{6}{|l|}{ Sex } \\
\hline Female & 380 & 28 & 1 & & \\
\hline Male & 403 & 46 & 1.3 & $0.84-2.0$ & 0.232 \\
\hline \multicolumn{6}{|l|}{ Histology } \\
\hline All other & 467 & 28 & 1 & & \\
\hline Basal cell carcinoma & 124 & 16 & 2.1 & $1.3-3.4$ & 0.004 \\
\hline Squamous cell carcinoma & 192 & 30 & 1.8 & $1.3-2.6$ & $<0.001$ \\
\hline \multicolumn{6}{|l|}{ Body site } \\
\hline All other & 598 & 42 & 1 & & \\
\hline Legs and feet & 142 & 25 & 1.9 & $1.1-3.1$ & 0.019 \\
\hline Thighs & 43 & 7 & 2.2 & $1.3-3.6$ & 0.002 \\
\hline \multicolumn{6}{|l|}{ Diabetes mellitus } \\
\hline No & 765 & 70 & 1 & & \\
\hline Yes & 18 & 4 & 1.7 & $1.4-2.2$ & $<0.001$ \\
\hline \multicolumn{6}{|l|}{ Date of excision } \\
\hline Dry season & 521 & 47 & 1 & & \\
\hline $\begin{array}{l}\text { Wet season (December to } \\
\text { February) }\end{array}$ & 262 & 27 & 1.1 & $0.72-1.6$ & 0.723 \\
\hline \multicolumn{6}{|l|}{ Other medical condition* } \\
\hline No & 769 & 70 & 1 & & \\
\hline Yes & 14 & 4 & 2.2 & $0.43-10.9$ & 0.353 \\
\hline \multicolumn{6}{|l|}{ Wound management } \\
\hline Dry group & 378 & 37 & 1 & & \\
\hline Wet group & 405 & 37 & 0.95 & $0.78-1.1$ & 0.577 \\
\hline
\end{tabular}

* Other medical conditions recorded were chronic obstructive pulmonary disease (8), anaemia (1), "aspirin" (2), "steroids" (3), "warfarin" (2), ischaemic heart disease (1), and peripheral vascular disease (1). The model was adjusted for the cluster sampling design and for the confounding effects of age and sex of the participants. Date of excision, presence of other medical condition, and wound management were not part of the model.

recorded. The differences in infection rates we observed between centres have to be seen as resulting from a combination of patient, wound, and treatment factors, as well as doctor factors.

The diagnosis of infection, even when using guidelines, is still subjective, and has inter- and intra-observer variation. ${ }^{15}$ The definition of infection we used has limitations, but it is the most widely implemented standard definition of wound infection, ${ }^{15}$ and was as close to a gold standard as we could find. We have no information regard- ing intra- and inter-practice reproducibility of measurement and recording procedures.

In addition, there are some limits to generalising these findings. The GPs involved were not representative of Australian GPs, being younger and more predominantly female. ${ }^{16}$ The population of Mackay is slightly older and has a lower median household income than the Australian population. ${ }^{17}$ Mackay is a provincial town in tropical north Queensland and has a hot and humid climate, with the mean daily maximum temperature ranging between $24^{\circ} \mathrm{C}$ 
and $30^{\circ} \mathrm{C}$ during the summer months, and a relative humidity of $75 \%-79 \% .{ }^{18}$ Our findings may not be generalisable to a temperate climate, although there is no published evidence that heat and humidity increase infection rates.

Antibiotic prophylaxis is probably prescribed excessively or inappropriately for dermatological surgery, ${ }^{1,19}$ and is thought to be best reserved for high-risk patients. ${ }^{19,20}$ There are no data available on the current prescribing habits of Australian GPs regarding antibiotic prophylaxis for minor excisions. Although there is also no evidence available regarding what reduction in the rate of infection we might reasonably expect from the use of prophylactic antibiotics for minor excisions, there is some evidence of a $50 \%$ reduction in risk of infection when perioperative antibiotic prophylaxis is used following clean surgery. ${ }^{21}$ In addition to efficacy, antibiotic costs, adverse effects and resistance must be taken into account when considering their use prophylactically. However, our results could encourage more judicial use of prophylactic antibiotics by defining high-risk groups for infection in a general practice setting, such as people with diabetes and those undergoing excision of a non-melanocytic skin cancer or excision from a lower limb. Alternatively, other nonpharmaceutical interventions aiming to reduce infection rates could be targeted towards these high-risk groups.

\section{ACKNOWLEDGEMENTS}

We thank the participating GPs and practice nurses. This project was funded by a Novice Researcher scholarship from the Primary Health Care Research, Evaluation and Development fund through James Cook University. We also thank Ms Lisa Crossland for her support as Primary Health Care Research, Evaluation and Development coordinator.

\section{COMPETING INTERESTS}

None identified.

\section{AUTHOR DETAILS}

Clare Heal, MB ChB, DRACOG, FRACGP, Senior Lecturer ${ }^{1}$

Petra Buettner, MSc, PhD, Senior Lecturer ${ }^{1}$

Sheldon Browning, DRACOG, DipDerm,

FRACGP, General Practitioner ${ }^{2}$

1 James Cook University, Mackay, QLD.

2 Mackay, QLD.

Correspondence: clarshel@hotmail.com

\section{REFERENCES}

1 Mangram AJ, Horan TC, Pearson ML, et al. Guideline for prevention of surgical site infec- tion, 1999. Infect Control Hosp Epidemiol 1999; 20: 250-278.

2 Cruse JE, Foord R. The epidemiology of wound infection. Surg Clin North Am 1980; 60: 27-40.

3 Nguyen D, MacLeod WB, Phung DC, et al. Incidence and predictors of surgical-site infections in Vietnam. Infect Control Hosp Epidemiol 2001; 22: 485-492.

4 Amici J, Rogues A, Lasheras A, et al. A prospective study of the incidence and complications associated with dermatological surgery. $\mathrm{Br} \mathrm{J}$ Dermatol 2005; 153: 967-971.

5 Furtoryan T, Grand D. Postoperative wound infection rates in dermatologic surgery. Dermatol Surg 1995; 21: 509-514.

6 Dettenkofer M, Wilson C, Ebner W, et al. Surveillance of nosocomial infections in dermatology patients in a German university hospital. $\mathrm{Br}$ J Dermatol 2003; 149: 620-623.

7 National Primary Care Research and Development Centre and Centre for Public Policy and Management, University of Manchester. Outpatient services and primary care. A scoping review of research into strategies for improving outpatient effectiveness and efficiency. Manchester: NPCRDC, 2006. http:// www.npcrdc.man.ac.uk/Publications/final_ report.pdf (accessed Jan 2006).

8 Lathlean S. Skin cancer in general practice in South Australia. A five year study. Aust Fam Physician 1999; 28 (Suppl 1): S28-S31.

9 Del Mar CB, Lowe JB. The skin cancer workload in Australian general practice. Aust Fam Physician 1997; 26 (Suppl 1): S24-S27.

10 Marks R. Dermatology for the non-dermatologist. Med J Aust 1996; 164: 430.

$11 \mathrm{O}^{\prime}$ Cathain A, Brazier J, Milner PC, Fall M. Cost effectiveness of minor surgery in general prac- tice: a prospective comparison with hospital practice. Br J Gen Pract 1992; 42: 13-17.

12 Heal C, Buettner P, Raasch B, et al. 'Can sutures get wet?' $A$ randomised controlled trial of wound management in general practice. BMJ 2006; 332: 1053-1056.

13 Sylaidis P, Wood S, Murray DS. Postoperative infection following clean facial surgery. Ann Plast Surg 1997; 39: 342-346.

14 Nagachinta T, Stephens M, Reitz B, Polk BF. Risk factors for surgical wound infection following cardiac surgery. J Infect Dis 1987; 156: 967973.

15 Bruce J, Russell EM, Mollison J, Krukowski ZH. The quality of measurement of surgical wound infection as the basis for monitoring: a systematic review. J Hosp Infect 2001; 49: 99-108.

16 Britt $H$, Knox S, et al. General practice activity in Australia 2000-2001. Sydney: University of Sydney, 2001.

17 Australian Bureau of Statistics. Basic community profile. CLIB 2001. 2001 Census of Population and Housing. Canberra: ABS, 2001. (ABS Cat. No. 2024.0.)

18 Australian Government Bureau of Meteorology. Climate averages. Mackay MO: http:// www.bom.gov.au/climate/averages/tables/cw_ 033119.shtml (accessed Jul 2006).

19 Messingham MJ, Arpey CJ. Update on the use of antibiotics in cutaneous surgery. Dermatol Surg 2005; 31: 1068-1078.

20 Cho CY, Lo JS. Dressing the part. Dermatol Clin 1998; 16: 25-47.

21 Platt R. Antibiotic prophylaxis in clean surgery: does it work? Should it be used if it does? New Horizons 1998; 6 (2 Suppl): S53-S57.

(Received 28 Feb 2006, accepted 18 Jul 2006) 